\title{
LA AUDIENCIA TELEVISIVA. UNA APROXIMACIÓN TEÓRICA A LA EFICIENCIA Y LEGITIMIDAD DE LAS AUDIENCIAS
}

\section{TV AUDIENCE. A THEORETICAL APPROACH TO THE EFFICIENCY AND LEGITIMACY OF AUDIENCE}

\author{
Xabier Martínez-Rolán ${ }^{\text {: }}$ Universidad de Vigo (España) \\ xabier.rolan@uvigo.es
}

\section{RESUMEN}

En el momento televisivo actual, superada la liberalización del mercado en España en los años 90 y en plena expansión de licencias televisivas al albor de la digitalización del servicio, se ha multiplicado la oferta televisiva en beneficio del telespectador. Sin embargo, la multiplicación de canales no ha implicado la calidad ni la diversidad de los contenidos televisivos emitidos.

Grupos mediáticos y cadenas de televisión justifican su oferta de programación basándose en los criterios de audiencia y, en relación a éstos, a la demanda real de la audiencia. No obstante, ¿es realmente así? ¿Es la audiencia quien decide qué contenidos se programan, o se adapta a la oferta emitida?.

El objetivo de este trabajo es realizar una aproximación al concepto de la elección de la audiencia y su relación con la programación televisiva, desde una perspectiva teórica.

PALABRAS CLAVE: Televisión - eficiencia - legitimidad - educación alfabetización audiovisual- Parrilla televisiva - Ética

\section{ABSTRACT}

Nowadays TV, surpassed Spanish market liberalization in the 90's, and in a process of TV licenses expansion due to the digitalization of the service, television has multiplied the offer in benefit of the viewer. But, the increase in audiovisual shows and programs has not grown even to the quality of television content broadcasting. Media groups and broadcasters justify their product based on audience criteria and, so on, the actual demand of the audience. However, is it really so? Is the audience who decides which content is programmed, or it adapts to tender issued?. The objective of this work is to approach the concept of the choice of the audience from the proposed television programming, from a theoretical perspective.

\footnotetext{
1'Xabier Martínez-Rolán: Doctor en Comunicación por la Universidad de Vigo (2016) desarrolla su carrera profesional en el ámbito de la comunicación online y el marketing digital. Después de sus primeros trabajos en el campo de la comunicación en los medios tradicionales, ha sido parte del equipo de producción de varios programas de radio y televisión, y desde 2009 es un profesional independiente para la gestión de comunicación en línea; principalmente en plataformas de gestión de redes sociales y contenido web. También es profesor asociado del Departamento de Comunicación Audiovisual y Publicidad de la Universidad de Vigo, donde imparte asignaturas relacionadas con aplicaciones móviles (licenciatura en Comunicación Audiovisual), comunicación alternativa y marketing online (licenciatura en Publicidad y Relaciones Públicas). Sus áreas de investigación, junto con las de trabajo, se centran en la comunicación y movilidad en línea, nuevos formatos de publicidad y comunidades virtuales. Correo institucional: xabier.rolan@uvigo.es
} 
KEY WORDS: Television, Efficiency, Legitimacy, Education, Audiovisual educationTV grid - Ethics

\section{Cómo citar el artículo:}

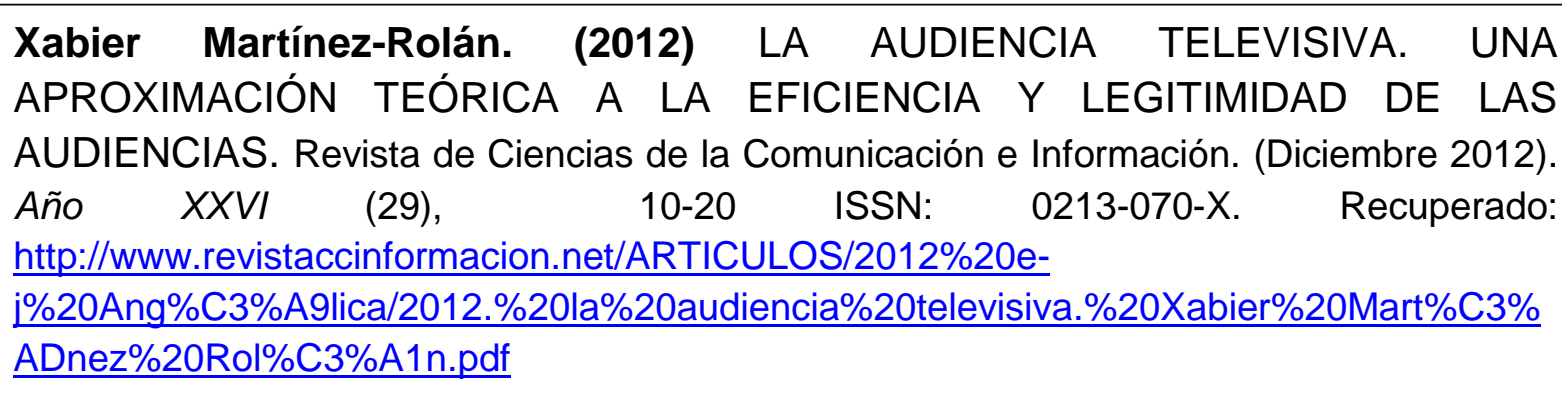

\section{INTRODUCCIÓN}

Desde la liberalización del mercado televisivo en los '90 con la aparición de las cadenas de televisión privadas (y fruto del marco regulatorio liberalizador de los años '80) la oferta televisiva española ha crecido a un ritmo vertiginoso. La multiplicación de los canales, pese a la reciente reconcentración de los medios, ha implicado el incremento de la oferta televisiva. No obstante, se trata más de un incremento cuantitativo que cualitativo en tanto que la oferta televisiva es múltiple, pero no diversa; y no ha sido acompañada de una mejora de la calidad de los contenidos.

La llamada telebasura, fenómeno caracterizado por la explotación del morbo, el sensacionalismo y el escándalo como fórmulas de atracción de la audiencia, ha colonizado las parrillas televisivas. Aunque no se puede generalizar, esta tipología de contenidos son más frecuentes en determinados programas de entretenimiento, como magazines, realities o talk shows y, en menor medida, concursos y debates.

Ante la ambigüedad de la definición del fenómeno, el Consejo Audiovisual de Catalunya (2004) propone una definición de telebasura como aquel conjunto de programas que atentan contra la vulneración de derechos fundamentales y la falta de consideración hacia los valores democráticos o cívicos.

Así, podría considerarse telebasura el programa que utilice el desprecio a la dignidad que toda persona merece, el poco o ningún respeto a la vida privada o a la intimidad de las personas y la utilización de un lenguaje chillón, grosero e impúdico.

La intencionalidad de este tipo de pautas es clara: convertir en espectáculo la vida de determinados personajes que, generalmente, se prestan a ser manipulados a cambio de la celebridad que les da la televisión o a cambio de contraprestaciones económicas. (Consell de l'Audiovisual de Catalunya, 2004).

La gravedad de la cuestión estriba en la función de servicio público que ha de cumplir la televisión; función que se encuentra formulada en la normativa legal que regula la actividad televisiva. 
Muñoz Machado (1998) señala que la noción del servicio público en televisión es esencialmente una limitación a la libertad de comunicación que consiste en el establecimiento de obligaciones a los operadores de televisión públicos y privados.

Esta limitación tiene por objeto salvaguardar algunos derechos y libertades constitucionales, sin descuidar otros valores, educativos y culturales, a los que la televisión, como medio de gran penetración social, debe prestar una especial atención.

En un contexto de recesión económica, los programas que pueden catalogarse dentro de la definición de telebasura suponen una oportunidad en tanto que exigen un esfuerzo económico mucho menor que otro tipo de productos más costosos y elaborados como series.

Las cadenas de televisión justifican la emisión de contenidos en relación con la audiencia Programan los contenidos porque son los índices de audiencia quienes juegan un papel decisivo a la hora de fijar el precio de las inserciones publicitarias: la base de su modelo de negocio (para casi todas las televisiones).

Este artículo parte de la pregunta que todo telespectador tiene derecho a preguntarse: ¿elige realmente la audiencia lo que quiere ver?

\section{OBJETIVOS}

El objeto de este texto es efectuar una aproximación a la elección de los telespectadores y su relación con la oferta programática.

En un entorno tan dinámico, cambiante y poroso como es la comunicación es necesario mostrar un espíritu crítico ante la óptica funcionalista y la medición cuantitativa de la de audiencias.

Derivado de lo anterior, se profundiza en el concepto del índice de audiencia para justificar la programación de contenidos.

\section{METODOLOGÍA}

Este artículo efectúa una aproximación al concepto de las audiencias y la elección del telespectadora partir de la revisión bibliográficas y la construcción de un corpus teórico de gran valor.

Para la realización de este artículo se ha empleado el método teórico-lógico, La reproducción teórica de un objeto, en el pensamiento, de forma objetiva y concreta es parte del desarrollo de su comprensión. Obviando el método histórico, los métodos lógicos se utilizan para investigar las leyes generales y esenciales del funcionamiento y desarrollo de los fenómenos, hechos y / o procesos.

Lo lógico reproduce en el plano teórico, lo más importante del fenómeno, proceso o hecho, de lo histórico, lo que constituye su esencia. Así, y dado que este método permite reflejar el objeto en sus conexiones más esenciales, ofrece la posibilidad de 
comprender su funcionamiento, y permite unir el estudio de la estructura del objeto de investigación y la concepción de su historia.

\section{DISCUSIÓN}

\subsection{TV en el mercado: los índices de audiencia}

En un contexto televisivo de gran competencia que se refleja en las parrillas, contenidos y comunicadores, se ha consolidado el sistema de medición de audiencias como un indicador válido en la relación de las cadenas con el mercado y -por extensión- con la inversión publicitario.

El sociólogo francés Pierre Bordieu señaló en su ensayo "sobre la televisión" que: Los índices de audiencia significan la sanción del mercado, de la economía, es decir, de una legalidad externa y puramente comercial, y el sometimiento a las exigencias de este instrumento de mercadotecnia es el equivalente exacto en materia de cultura de lo que es la demagogia orientada por los sondeos de opinión en materia de política. La televisión gobernada por los índices de audiencia contribuye a que pesen sobre el consumidor supuestamente libre e ilustrado las imposiciones del mercado, que nada tienen que ver con al expresión democrática de una opinión colectiva ilustrada, racional, de una razón pública, como pretenden hacer creer los demagogos cínicos. Los pensadores críticos y las organizaciones encargadas de expresar los intereses de los dominados están muy lejos de analizar claramente este problema.(Bordieu, 1997:pag. 96-97)

En la reflexión de Bourdieu se encuentran dos claves que permiten un acertamiento a la los índices de audiencia y a su papel configurador de la realidad televisiva.

En la primera de ellas, "Los índices de audiencia significan la sanción del mercado, de la economía". Las diferentes cadenas de televisión configuran un mosaico de gestiones cuyo eje central es la rentabilidad económica (Bustamante, 1999), por lo que es posible diferenciar varios tipos de televisiones atendiendo exclusivamente al criterio económico (Sánchez-Tabernero, 2005):

- Televisiones públicas y autonómicas: en el caso español engloba a las cadenas de televisión públicas del grupo RTVE y todos los canales autonómicos que operan en régimen de concesión con financiación pública.

- Televisiones privadas: engloba a las operadoras que operan las licencias de televisión concedidas por el Estado para todo el territorio español o un ámbito más restringido y que son, además de privadas, abiertas y gratuitas.

- Televisiones locales: forman parte de este punto aquellas televisiones comarcales o regionales que han encontrado un hueco en el mundo globalizado y da salida a los anunciantes locales, al tiempo que ofrece información local, más próxima y cercana al espectador.

Cada día más, estos tres tipo de televisión pueden ser consideradas como "televisión publicitaria" si entendemos que su financiación es eminentemente 
publicitaria. Salvo el caso de RTVE, que ha prescindido de la financiación publicitaria en su última gran reforma (Piedrahita, 2010), todas las televisiones públicas y locales, con independencia de su financiación pública, participan del mercado publicitario bajo las mismas premisas y condiciones que las televisiones privadas.

Para completar la clasificación de Sánchez-Tabernero deberían incluirse los modelos televisivos no gratuitos, que en España están representados por la televisión de pago:

- Televisión de pago: engloba a aquellas operadoras que apoyan parte de su financiación de modo directo sobre el cliente final, que paga por los servicios consumidos, bien sea a través de una cuota fija o por programa consumido. Este tipo de televisión trata de ganar público compitiendo a través de una oferta diferenciada y/o una política de precios más o menos agresivas con respecto a sus competidores. En España es una opción que está ganando peso, aunque su porcentaje sobre el total de consumo televisivo es relativamente minoritario, alrededor del 7\% en 2011 (Sánchez-Tabernero, 2011).

La naturaleza económica de la televisión no es una cuestión baladí. Con independencia del rigor de su medición, el consumo televisivo en España en el momento actual se establece en función del índice de audiencia.

Un índice que se convierte en el indicador principal para determinar el valor económico de las inserciones publicitarias, al tiempo que permite atraer a nuevos anunciantes. El peso del factor económico es decisivo en el mercado televisivo, en tanto que la publicidad constituye el principal motor del medio.

A tales efectos, las empresas anunciantes han impulsado, desde los orígenes de la propia publicidad televisiva, sistemas que permitan conocer el número de telespectadores de sus contenidos y -por ende- el posible público de sus inserciones publicitarias. El objetivo último de estos sistemas de medición es ofrecer datos plausibles a los anunciantes para demostrar el retorno de inversión.

De esta manera, se ha prestado una atención excesiva al índice de audiencia como indicador infalible de la medición televisiva. Es así como cobra sentido la segunda frase destacada del la reflexión de Bourdieu:

La televisión gobernada por los índices de audiencia contribuye a que pesen sobre el consumidor supuestamente libre e ilustrado las imposiciones del mercado. Esto significa que las reglas del mercado televisivo parten con una clara ventaja a la hora de configurar una relación con la audiencia en la que las decisiones individuales se verán influidas por una mayoría configurada de antemano por el sector televisivo.

El público se entiende como receptor anónimo y disperso de los contenidos televisivos; una definición fuertemente influenciada por la óptica funcionalista de los estudios y teorías tradicionales de comunicación. En tanto que ese público disperso forma parte de una comunidad, de la que el espectador de manera autónoma no sería capaz de alienarse, la minoría creadora de los contenidos televisivos impondría 
su oferta programática.

Para profundizar en esta cuestión es necesario señalar las diferentes perspectivas de la audiencia televisiva. El acto de "ver la televisión "es, en primera instancia, un acto individual, materializado en la elección limitada entre el abanico de las ofertas posible en cada horario determinado y en función del tiempo disponible de cada espectador.

No obstante, ese consumo individual se diluye si tenemos en cuenta el carácter familiar [la elección de canal puede estar determinada por la jerarquía familiar y las relaciones de fuerza y negociación desigual en el seno de la familia nuclear (Bustamante 1999:134)] y el carácter social (es un acto influido como cualquier otro por el efecto de las modas, la innovación tecnológica, el efecto de "distinción" entre sus consumidores...). Esta circunstancia se hace especialmente patente cuando hablamos de una televisión social (Oehlberg et al., 2006) donde la fuerte irrupción de plataformas sociales como Twitter (Greer\& Ferguson, 2011) ofrecen una experiencia más colaborativa y plural de consumo televisivo.

\subsubsection{Métodos de medición de audiencia}

A lo largo de la historia de la medición de audiencias en televisión, se han empleado diversos métodos de recogida de datos, entre los que Huertas (1998) destaca tres, sintetizados y clasificados, mostrando sus avances con respecto a la generación anterior de anuncios:

(1) Encuesta por entrevista: es el método que se aplicaba sobre sondeos continuos periódicos y que se apoyaba en la figura del encuestador.

(2) Panel con diario de escucha: técnica en la que desaparecía el encuestador y se le pedía a cada uno de los componentes de la muestra (que en este caso era siempre un panel) que anotasen diariamente su consumo de televisión en un impreso - diario de escucha - que funcionaba como una entrevista escrita.

(3) Panel audimétrico: resulta de la utilización del audímetro, un aparato que, conectado al receptor de televisión, mide la audiencia de este medio de forma automática y permanente. Los audímetros modernos realizan las siguientes funciones:

1. Detecta el momento exacto en que se enciende y apaga el televisor.

2. Identifica el canal que se está visionando.

3. Identifica a la/s persona/s que visiona/n el canal, a través de un código que se marca en el mando a distancia.

4. Recogen el funcionamiento del vídeo doméstico, permitiendo detectar los programas gravados.

5. Almacena esta información.

6. Transmite esta información a un ordenador central, situado en la sede de la compañía responsable del sistema de audiometría.

La medición de audiencias, por tanto, se convierte en un sistema de medición aparentemente eficaz, aparentemente legítimo, apenas cuestionable desde el punto de vista cualitativo y base para la medición de los factores económicos de la 
televisión.

\subsection{La legitimidad de los estudios de audiencias}

No obstante, a pesar lo escrito con anterioridad, se hace necesario cuestionar la legitimidad y el grado de validez de los estudios de medición de audiencias.

La medición de audiencia en televisión se elabora, ante todo, basándose en variables única y exclusivamente cuantitativas; es un estudio cuantitativo, y como trabaja datos estimados, apenas aporta algunos datos de índole cualitativa. La finalidad esencial es determinar la extensión o tamaño del conjunto de telespectadores y, aunque éstos son clasificados a partir de diferentes variables poblacionales, no aportan los datos suficientes para señalar cómo es el telespectador y cómo funcionan sus elecciones ante el televisor.

Por ello, es necesaria la realización de estudios cualitativos para complementar las mediciones. Unos estudios que permitan diferenciar entre el espectador que ve la televisión por costumbre, con independencia de los contenidos, y el espectador selectivo, esto es, el que visiona únicamente los espacios que le interesan.

Se trata de una división esencial para la estrategia publicitaria, en un contexto de inflación comunicativa, donde las inserciones tienen cada vez un menor impacto.

Así, se busca conocer cuántas impresiones recibe el telespectador y, sobre todo, cómo y por qué.

Huertas (1998) apunta que los actuales estudios apenas aportan datos sobre las preferencias de los telespectadores, solo demuestran a qué horas está conectado el receptor o a qué horas está más disponible para actuar de telespectador. Esta autora se apoya en la metodología de Souchon quién propone una triple perspectiva para la medición de audiencias.

a) ¿Por qué se ve la televisión?

b) ¿Cómo se ve?

c) ¿Qué opinión le merece al telespectador?

Los diferentes sistemas que a lo largo de los años se han utilizado para el recuento son incapaces de llegar a todos los telespectadores, por lo que los estudios se fundamentan en una porción o muestra representativa del universo sobre el que se quiere obtener la cuantificación. En este contexto cobra relevancia el margen de error muestral.

El margen de error muestral, o tolerated error, da cuenta de la diferencia que existe entre los resultados que aporta una determinada muestra y los que se habrían obtenido en caso de cuestionar al censo total. Éste es un error inherente a las técnicas de muestreo, y sistemático, por lo que puede llegar a producir resultados sesgados o aleatorios.

Por ello, las cifras de audiencia, hasta ahora un criterio incuestionable, deben matizarse y entenderse en su contexto de probabilidad. Para Huertas (1998, pág.11 ), "las cifras de audiencia, más o menos millonarias, que se manejan con tanta 
rotundidad, son una pura estimación que se obtiene al extrapolar al universo los resultados obtenidos al interrogar sólo a una pequeña porción del mismo"

Por otra parte, Hugo Aznar (2002) asegura que la legitimidad del sistema de audiencias se basa en suponer que se da a la gente lo que ésta verdaderamente prefiere y eso significa que lo prefiere libremente. Se tata de un ejemplo más de la falacia naturalista que Hume describió hace más de 100 años, el pase indebido del "es" al "debe", ya que se está confundiendo lo que la gente verdaderamente prefiere con lo que la gente prefiere libremente.

La decisión se establece en torno al mando a distancia y a la oferta de contenidos que las cadenas ponen a disposición del espectador. Pero para que esta elección fuese realmente tal, la decisión de elección de canal por parte del telespectador tendría que ser una elección racional y no impulsiva.

Retomando la cuestión de la preferencias, existe una clara diferenciación entre las preferencias manifiestas y las informadas.

Preferencias manifiestas son preferencias reales tal y como se manifiestan en la conducta observada de un individuo, incluyendo las preferencias basadas en creencias erróneas sobre hechos, en análisis lógicos realizados de prisa y sin razonamiento o en emociones fuertes que en algún momento entorpecen la elección racional. Es por ello que son preferencias no informadas.

Por el contrario, preferencias informadas son aquellas que tendría un individuo si tuviera toda la información relevante sobre los hechos; si razonase con el mayor detenimiento posible y pudiese realizar una verdadera elección racional.

Diferenciar entre varios tipos de preferencias adquiere más relevancia en la concepción contemporánea de bienestar como satisfacción de preferencias(propuesta por Bentham), y que en la actualidad obliga a considerar lo esencial en la calidad de vida de los ciudadanos.

La elección de un determinado canal es la manifestación práctica de una preferencia de un telespectador. Aznar (2002)señala que las preferencias de los telespectadores son, en la mayoría de los casos, preferencias manifiestas.

El espectador, en su sillón, no tiene, en la mayoría de los casos, toda la información sobre los contenidos televisivos que va a ver, por lo que la elección que escoge con su mando a distancia se trata de una elección no informada. Es, en definitiva, una elección no libre, aunque sea voluntaria.

El actual sistema de audiencias identifica una decisión libre con una elección espontánea. Se trata esta de una correlación no probada, porque para que una elección sea libre son necesarias varias circunstancias:

- Racionalidad: que las partes implicadas basen sus criterios en la racionalidad

- Información veraz y honestidad: la información transmitida entre ambas partes ha de ser veraz y acorde con el universo cultural que rodea la relación. 
- Voluntariedad: tanto la coerción como la falta de voluntariedad anulan una elección racional.

Se podría realizar una analogía entre la elección de un canal y la compra de un producto para explicar esta cuestión. Cuando una persona compra un producto, el vendedor no enseña las posible desventajas, o bien seduce al comprador para que adquiera el mismo sin tener en cuenta sus verdaderas necesidades. Así, en la elección espontánea de un determinado canal, el telespectador puede consumir un programa cuyo contenido no se ajusta a lo que espera en un primer momento, seducido por la impresión que causan las primeras imágenes, una reseña o el propio nombre del programa.

Con todo es necesario señalar que la interpretación del bienestar como satisfacción de preferencias no admite que cualquier clase de preferencia haya de ser satisfecha, sino que intuye una jerarquía o límites.

Por ello, las televisiones no tienen obligación de ofrecer programas de baja calidad o que puedan ser tildados de "telebasura" con los que satisfacer ese tipo de preferencias entre su público.

Para finalizar con la argumentación en torno a las preferencias de los telespectadores, y suponiendo que las elecciones sean todas racionales y plenamente libres, podría darse el caso de que eso no bastase para garantizar que las preferencias de la gente cambiaran radicalmente (Aznar, 2002). Es posible que, aún a pesar de una elección libre e informada, la gente siguiera prefiriendo programas que se encuadrasen dentro del marco de la "telebasura".

Sin embargo, también cabe la posibilidad de que cambiase el sistema televisivo actual. Al fin y al cabo, existen otros modelos televisivos europeos que son un referente de ámbito mundial sobre calidad en televisión. El ejemplo más claro es el canal británico ChannelFour.

El caso de ChannelFour, que en 1982 se asoció a ITV, merece una atención aparte. Es probablemente la experiencia más interesante para los defensores de la calidad en la programación. Fue un canal creado para abrir la puerta a nuevas ideas y creaciones, dar una vía de acceso a los intereses de los grupos minoritarios, étnicos y profesionales, con una programación de espacios informativos especializados, un gran cuidado de la calidad formal y con experimentación de nuevas formas que van de los 4 a los 15 minutos (Vilches, 1993: pág.175)

En síntesis, la programación televisiva no representa precisamente un contexto de elección libre.

\section{CONCLUSIONES}

Este texto evidencia la correlación que existe entre los programas que forman parte de la "telebasura" y la justificación de su oferta por sus índices de audiencia. Esta correlación pone de manifiesto los riesgos de mantener un sistema de medición de audiencias como el actual, basado en criterios únicamente cuantitativos y que no 
aportan datos cualitativos.

El sistema audimétrico basa su criterio en la libertad del espectador para elegir el canal, una afirmación que se ha rebatido en el presente texto, manifestando la carencia de información por parte del telespectador. Es necesario avanzar y proponer soluciones al respecto que, en todo caso, pasan por una toma de decisión del espectador verdaderamente informada que de legitimidad al sistema audimétrico.

Como remedio a la telebasura se propone un refuerzo sobre la educación mediática (media literacy o media education) como el proceso de enseñar y aprender sobre los medios.

El desarrollo de las capacidades críticas y creativas del espectador respecto a los medios que consume podría reforzar la capacidad para realizar una preferencia informada a la hora de consumir una u otra alternativa televisiva.

El consumo crítico de la televisión promovido desde una alfabetización audiovisual puede ayudar a la configuración de nuevos telespectadores verdaderamente libres que den legitimidad a los estudios de audiencias.

Dicha alfabetización puede ser integrada como una asignatura dentro del sistema educacional actual o como una obligación moral de los padres cara sus hijos en una sociedad hipermediatizada y con fuerte peso de los medios de comunicación.

En definitiva, se aboga por la extensión de un consumo crítico a partir del desarrollo de una previa educación mediática.

\section{REFERENCIAS:}

Aznar H, (2002). "Televisión, telebasura y audiencia", en Revista Latina de Comunicación Social, número 48, de marzo de 2002, La Laguna (Tenerife). Consultado el 12 de Marzo del 2012 en la siguiente dirección telemática (URL)http://www.ull.es/publicaciones/latina/2002/latina48marzo/4807aznar2.htm

Bordieu, P. (1997).Sobre la televisión Barcelona: Editorial Anagrama

Bustamante, E. (1999).La televisión económica. Barcelona: Ed. Gedisa

Consell De L'Audiovisual De Catalunya, (2004). Consideraciones del CAC sobre la telebasura,Consultado el 12 de noviembre de 2009en la siguiente dirección telemática

(http://www.consejoaudiovisualdenavarra.es/actualidad/documents/consideracionest elebasura.pdf)

Garcia, P. (2002). El bienestar como preferencia y las mediciones de pobreza.Cinta de Moebio. Revista de Epistemología de Ciencias Sociales, (13). 
Greer, C. F., \& Ferguson, D. A. (2011). Using Twitter for promotion and branding: A content analysis of local television Twitter sites. Journal of Broadcasting \& Electronic Media, 55(2), 198-214.

Huertas, A. (1998).Cómo se miden las audiencias en televisión Barcelona: Editorial Cims 97 S.L.

Muñoz Machado, S (1998). Servicio publico y mercado Vol III, Madrid: Ed. Civitas.

Oehlberg, L., Ducheneaut, N., Thornton, J. D., Moore, R. J., \& Nickell, E. (2006, May). Social TV: Designing for distributed, sociable television viewing. In Proc. EurolTV (Vol. 2006, pp. 25-26).

Piedrahita, M. (2010). TVE en la encrucijada: el devenir de la televsión pública ante el nuevo reto de emitir sin publicidad. Guadalturia Ediciones.

Sánchez-Tabernero, A (2011). "La televisión en España. Informe 2011", En JORNADA ANUAL UTECA 2011, celebrado el 8 de noviembre de 2011. Consultado el 12 de Enero del 2012 en la siguiente dirección telemática (http://uteca.tv/download.php?dj=71)

Sánchez-Tabernero, A. (2005). El mercado televisivo europeo. La competencia entre las televisiones públicas y privadas. Telos: Cuadernos de Comunicación E Innovación, (63), 36-43.

Vilches, L. (1993): La televisión. Los efectos del bien y del mal. Barcelona, Paidós 